\title{
Digital Payment Adoption in India: Insights from Twitter Analytics
}

\author{
Prabhsimran Singh ${ }^{1}$, Yogesh K. Dwivedi ${ }^{2}$, Karanjeet Singh Kahlon ${ }^{3}$, \\ Nripendra P Rana ${ }^{4}$, Pushp P Patil ${ }^{5}$, Ravinder Singh Sawhney ${ }^{6}$ \\ ${ }^{1}$ Department of Computer Engineering \& Technology, ${ }^{3}$ Department of Computer Science, \\ ${ }^{6}$ Department of Electronics Technology, \\ ${ }^{1,3,6}$ Guru Nanak Dev University, Amritsar, India, \\ ${ }^{2,4,5}$ School of Management, Emerging Market Research Center (EMaRC), \\ ${ }^{2,4,5}$ Swansea University, Swansea, UK. \\ 1'prabh singh32@yahoo.com, ${ }^{2}$ y.k.dwivedi@swansea.ac.uk, ${ }^{3}$ karankahlon@gndu.ac.in, \\ nrananp@gmail.com, ${ }^{5}$ pushpppatil@gmail.com, ${ }^{6}$ sawhney.ece@gndu.ac.in,
}

\begin{abstract}
Ever since demonetization happened in India on November 8, 2016, there has been a steady improvement in the use of digital payments. The usage trend has become exponential in the last 15 months across the digital payment methods (DPMs) in India. Government of India is promoting this landmark change of Indian financial system through Digital India initiative. Both national and international corporates, established as well as startups are investing heavily in DPMs to promote their products and services among Indian consumers. The promotion of DPMs also includes the use of social media marketing. Social media (especially Twitter) is being extensively used by companies to make the consumer aware about their services and promote themselves. The consumers do get motivated to try and use their services but they also share their grudges on Twitter. This paper aims to analyze DPMs adoption in India using Twitter as a tool. This study collected 172996 tweets over a period of four months and analyzed using a mix of conventional as well novel social media analytics techniques. Our analysis highlights the critical factors that drive and inhibit the use of DPMs in India. Further, our state wise analysis clearly differentiates about DPM adoption rate from high to low in all states of India.
\end{abstract}

Keywords: Digital Payment, Mobile Payment, Sentiment Analysis, Social Media Analytics, Twitter

\section{Introduction}

With advancement in technology, the life of mankind has become both comfortable and convenient [1]. The one such technology that has revolutionized our lives is Internet [2]. One sector that has seen a complete makeover due to advancements in internet is the financial (Banking) sector, which has experienced a paradigm shift from use of traditional currency notes to use of digital payment methods (DPMs) [34]. The availability coupled with ease of use of mobile devices has taken DPMs to next level of banking that is, because of the additional capabilities that it offers in 
term of mobility and portability [2, 5-6]. Nowadays smart phones have become integral part of our life and the ease of use of the android apps shared by the various e-marketers (such as Amazon, Paytm mall, Domino's) are making users hooked to the technology in performing their day to day activities including financial transactions [1]. DPMs such as mobile payments or mobile wallets are becoming popular amongst users (especially youth) as these platforms provide direct transactions through smartphones [7-8].

Currently, transactions through DPMs are estimated around \$3,598,226 million of global GDP and are expected to be almost double i.e. $\$ 6,686,650$ million by 2023 [9]. With advantages such as transparency, better services, better delivery system, gradually more and more people are adopting DPMs. However, they have not been able to reach to their optimum potential in many developing as well as developed countries apart from few exceptions $[6,10]$. Given the above, this paper explores the potential of DPMs in India using Twitter as a tool. The reason for choosing Twitter is its ease of use among social media, which is becoming an important part of people's life [11]. The statistics suggest that an average person spends two and half hours daily on social media sites [12]. So, social media provides an ideal platform for both vendors and consumers (having common interest) to interact virtually [13]. It has been examined that the social media is being used by consumers who wish to express the acceptance or rejection of services. It has been suggested that vendors also utilize the potential of social media to promote their services and products [14-15].

The paper is structured as follows: Section 2 discusses the related work including DPMs, its background, its brief history with Indian context and importance of social media in our life. Section 3 gives details of our research methodology for this research work, followed by implementation and results in Section 4. Section 5 discusses the results and finally, we conclude in Section 6.

\section{Review of Literature}

Digital payment is a mode of making financial transactions using electronic medium and devices such as smart mobile phones and laptops [16]. DPMs provide convenient and time saving option as compared to traditional banking system [17]. In addition to this DPMs also provide various benefits to individuals (like ease of handling of cash, security from thefts) and nation (like removing corruption and black money). Since 1990 's, E-banking started becoming popular among educated users, however, the popularity and usage were restricted to users of mostly developed countries. By 2010, digital payments gained popularity all around the world and started getting adopted in many developed as well as developing countries as the data communication took up the pace [18]. With the availability of cheap and affordable data services as well as mobile devices, M-banking became more popular than its predecessor i.e. E-banking, as it eliminated the requirement of relying on a PC device or a Laptop with internet connection to make payments [19-21]. 
In India, DPMs saw an exponential growth after demonetization by the Government of India (GOI) on $8^{\text {th }}$ November, 2016 [22]. GOI promoted the DPMs as a part of Digital India Initiative which helped them in enhancing transparency, reduction in tax envision and improving public delivery system [23]. Most of the time when we talk about consumer oriented DPMs, it's the mobile payment systems (like M-banking) [24]. In Mobile based DPMs, the payments or the transactions are made using mobile devices having technologies like Near Field Communication (NFC) etc [25-26]. Portability and mobility are the major contributors in making Mobile based DPMs more popular than traditional DPMs (E-banking etc.) [27]. India currently has 530 million smart phones [28] and approximately 478 million users are using Internet on these mobile gadgets [29]. With Indian digital payment industry poised to reach $\$ 700$ billion by 2022 wherein Mobile based DPMs are expected to be playing a major role [30].

Nowadays Social Media has become an Integral part of our social life including routine daily chores [11]. Everyday people spend hours on social media to discuss and interact with like-minded people. In short, social media provides a perfect platform for people all around the world to discuss topics of common interest such as sports, entertainment and even digital payments [31-32]. Even the firms are aware of this fact, and hence various studies indicate that $96.43 \%$ of firms utilize the potential of social media to promote their services and products through social media marketing [14-15]. Important studies indicate that almost $80 \%$ of users on social media access information regarding sales and offers/deals related to promotion of various products [33]. This effective communication through the virtual world plays a crucial role in building a strong relationship between the user and the firm [34].

Despite the potential of DPMs in India and the numerous advantages it is offering to people in India, it has failed to reach its optimal potential in terms of its adoption by the Indian consumers. This difference in perception and execution has motivated us to take this research and carry out our analysis using data from Twitter. Through this research article, we try to the best of our understanding, to answer the following research questions: (a) What are the factors that influence the people to adopt DPMs? (b) What are all are the factors that inhibit consumers to adopt DPMs? Both these questions will be answered through analysis of the collected tweets posted by people on Twitter during our sampling period of 4 months.

\section{Research Methodology}

As mentioned earlier, to accomplish our research goals, the entire task has been divided into four phases. In phase-1, data was fetched from Twitter using Twitter API [35]. Since the collection of data is in unstructured json format, it becomes crucial to convert it into the structured format (excel format). So, in phase-2, we convert this unstructured data into structured format. Though, the data gets converted into structured format; still it contains a lot of noise and other redundant stuff (like web links etc.). Hence, it is essential to preprocess the data as these ambiguities can lead to 
superfluous results [36-37]. Phase-3 deals with data preprocessing, where we accomplish the entire task of preprocessing using R-Language [38]. Finally, in phase4 , the processed structured data is ready to be used to perform analysis using various social media analytics techniques [39-40].

\section{Implementation and Results}

The entire implementation of moderating the processed data collected from previous step has been done in R-Language using various text mining libraries. Towards better understanding of the readers, this section is further divided in various sub-sections, with each giving in depth details of each analysis.

\subsection{Data Collection}

As previously explained, we fetched data for our experimentation from Twitter using specific \#hashtags (\#DigitalPayment OR \#CashlessPayment OR \#Epayment OR \#Mpayment OR \#MobileMoney OR \#MobilePayment). In total, we collected 1,72,996 tweets 88,373 unique users over a period of four months (March 1, 2018 to June 30, 2018). This time duration was selected because March is the last month of Indian financial year while, the first quarter of the new financial year consists of other three months (April, May and June) and most of the financial activities take place during this duration. Since, the aim of this paper is to do detailed analysis of DPMs in the Indian context; hence, tweets were only collected from India. The detail of monthly tweets collection is shown in Figure 1, while Figure 2 shows categories of collected tweets regarding DPMs. Similarly, Table 1 shows detailed tweet statistics.

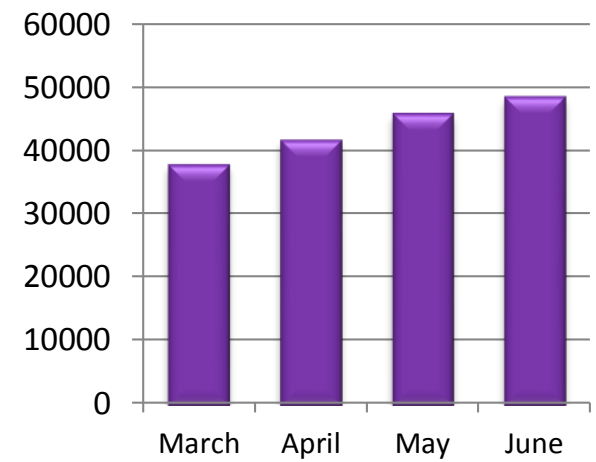

Figure 1. Tweet Collection Details

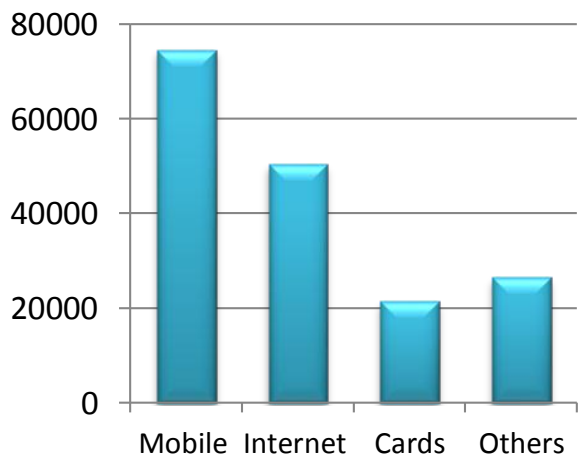

Figure 2. Tweet Categorization Details

Inference: The above stats clearly indicate the popularity of DPMs is rising among Indian people. Moreover, a major chunk of tweets were related to mobile payments and mobile wallets. Internet banking was second most popular DPM followed by cards (Credit and Debit cards). The rest of the tweets were related to other DPMs, 
bank promotions, government initiatives etc. Overall, the DPMs are becoming popular among Indian people. Further, more and more people are adopting this mechanism for making financial transactions with mobile payments and mobile wallets, being the most convenient and popular choice.

Table 1. Tweet Statistics

\begin{tabular}{|l|c|c|c|c|}
\hline & March & April & May & June \\
\hline Total Tweets & 37616 & 41427 & 45632 & 48321 \\
\hline Max Tweets in a Day & 2076 & 2646 & 2548 & 2977 \\
\hline Min Tweets in a Day & 92 & 63 & 71 & 106 \\
\hline Total Unique Senders & 14371 & 21674 & 25423 & 26905 \\
\hline $\begin{array}{l}\text { Average Tweets per } \\
\text { Sender }\end{array}$ & 2.617 & 1.911 & 1.794 & 1.795 \\
\hline $\begin{array}{l}\text { Average Tweet per } \\
\text { Month }\end{array}$ & 1213.41 & 1380.90 & 1472 & 1610.70 \\
\hline
\end{tabular}

\section{2 (\#) Hashtag Analysis}

Hashtags depicts what is trending on Twitter [41-42]. In total, we collected a total of $2,01,594$ Hashtags out of that we only retained unique 60,567 hashtags. With 24,647 occurrences, \#DigitalIndia was the most used hashtag. The association among top ten hashtags is shown in Table 2. The diagonal represents the occurrence for each hashtag, while other columns represent the amount of association with other hashtags.

Table 2. Association among different hashtags

\begin{tabular}{|c|c|c|c|c|c|c|c|c|c|c|}
\hline & 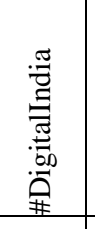 & 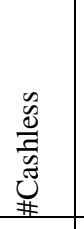 & $\begin{array}{l}\stackrel{\gtrsim}{0} \\
\sum_{0}^{0} \\
: 0 \\
\sum_{0}^{0}\end{array}$ & 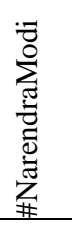 & 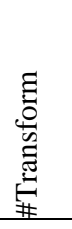 & 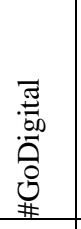 & 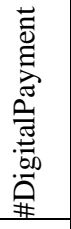 & $\begin{array}{l}\stackrel{0}{0} \\
\stackrel{0}{0} \\
0 \\
0\end{array}$ & 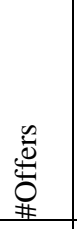 & 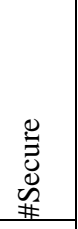 \\
\hline \#DigitalIndia & 24647 & 467 & 19 & 1001 & 362 & 19 & 214 & 257 & 427 & 246 \\
\hline \#Cashless & 467 & 3905 & 16 & 89 & 31 & 20 & 181 & 32 & 154 & 118 \\
\hline \#MobileMoney & 19 & 16 & 2296 & 21 & 34 & 29 & 31 & 23 & 125 & 53 \\
\hline \#NarendraModi & 1001 & 89 & 21 & 2154 & 34 & 42 & 14 & 38 & 53 & 17 \\
\hline \#Transform & 362 & 31 & 34 & 34 & 1615 & 18 & 37 & 24 & 67 & 33 \\
\hline \#GoDigital & 19 & 20 & 29 & 42 & 18 & 4540 & 16 & 54 & 22 & 42 \\
\hline \#DigitalPayment & 214 & 181 & 31 & 14 & 37 & 16 & 2413 & 51 & 74 & 137 \\
\hline \#Benefits & 257 & 32 & 23 & 38 & 24 & 54 & 51 & 1099 & 101 & 61 \\
\hline \#Offers & 427 & 154 & 125 & 53 & 67 & 22 & 74 & 101 & 1231 & 87 \\
\hline \#Secure & 246 & 118 & 53 & 17 & 33 & 42 & 137 & 61 & 87 & 1297 \\
\hline
\end{tabular}


Inference: We observed that most of the collected hashtags were related to digital and cashless payments (\#DigitalIndia, \#Cashless, \#MobileMoney, \#GoDigital, \#DigitalPayment). Since Prime Minister of India advocated heavily for digital payment systems, \#NarendraModi and \#Modi also featured in top hashtags. Since people get attractive offers from various vendors, \#Benefits and \#Offers were also among popular hashtags. Hashtags such as \#Reliable and \#Secure depict that people find these services secure and can rely upon. However, many users also used the hashtags with \#CyberSecurity emphasizing the need for bigger encryption security for the transaction policies [43]. Overall, the hashtags depict a mixed but biased positive attitude among all the users.

\subsection{Sentiment Analysis}

Sentiment analysis deals with extraction of sentiment from given piece of information regarding a particular entity [44-46]. It is widely considered as the most effective tool to map public opinion. The ultimate aim here is to detect the polarity of the view i.e. positive or negative for a given entity (tweets in our case). Figure 3 below shows the results of polarity analysis while Figure 4 shows the treemap of positive and negative words.

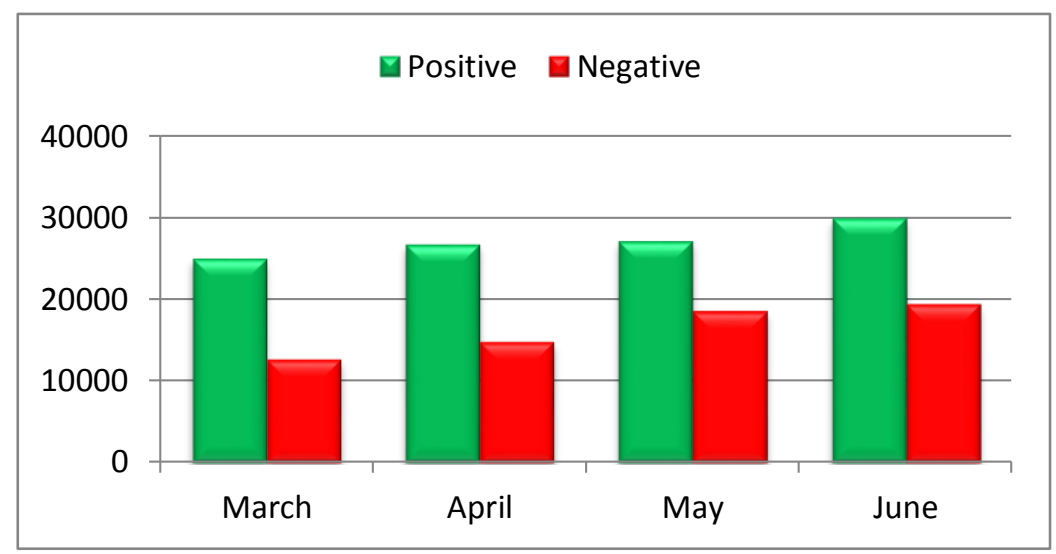

Figure 3. Results of Polarity Analysis

Inference: For the entire duration of four months, the positive polarity maintained its upper edge over the negative polarity, indicating the positive opinion of people using the digital technologies. However, there was a constant growth in number of negative tweets from March (33\%) to June (40\%), indicating that more people posted negative tweets in the later part of our sample period depicting their anger and displeasure after availing services from respective vendors. 


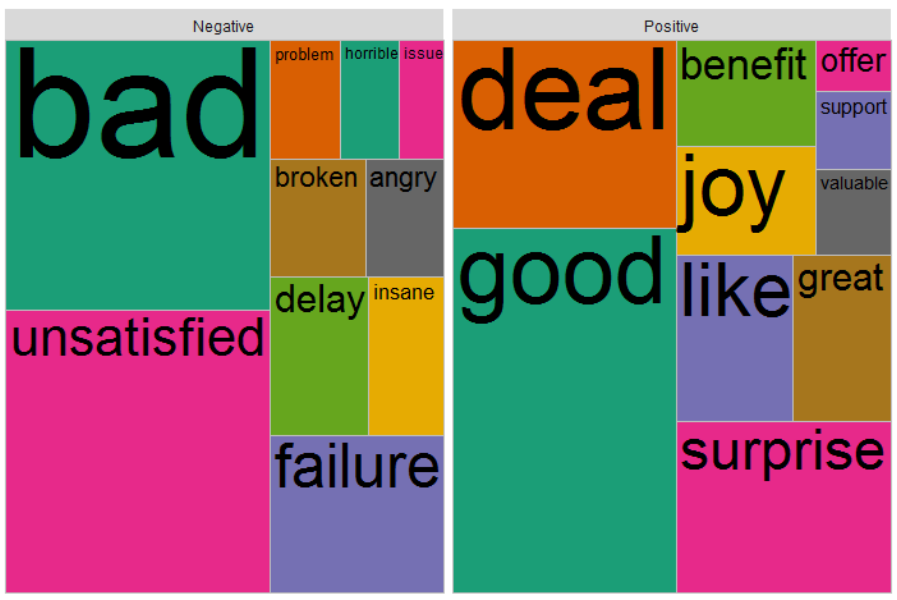

Figure 4. Treemap of Positive and Negative Words

\subsection{Network Analysis}

The use of network analysis approach is to detect prominent communities taking part in discussion regarding a particular entity [47]. The result of network analysis is shown in Figure 5. There are three prominent communities and a minor community.

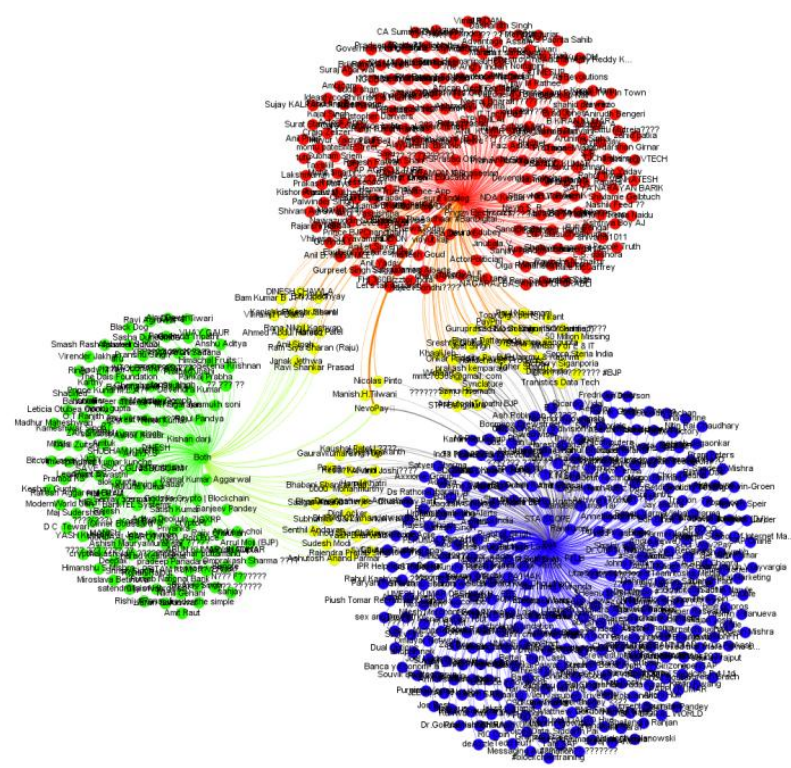

Figure 5. Results of Community Analysis

Inference: Figure 5 clearly depicts that there are three main communities. The blue nodes indicate the community of people who are posting positive tweets in favor of 
DPMs. This community is largest among the lot representing overall positive attitude among people regarding DPMs. The red nodes indicate the people who are posting negative tweets regarding DPMs. These are the people who are not willing to use DPMs and are critical of its efficacy. The green nodes indicate the community of people who were earlier supporting DPMs, but later started posting negative tweets after their experience with these activities might have went wrong. These people were once committed users of DPMs, but due to some technical issues or bad experiences turned against DPMs. Finally, we have the users, who are continuously switching among all three communities; these people are indicated with yellow nodes.

\subsection{Geo-Location Analysis}

Location based analysis is considered the most critical tool for mapping public response in an area of large demography towards an entity [48-50]. For a diverse country like India, location based analysis becomes even more crucial. Due to Twitter privacy policy, all the tweets were not geo-tagged. Hence, only geo-tagged tweets are considered for this analysis. The result of location based analysis is shown in Figure 6. Similarly, Figure 7 shows the top five cities with maximum DPM usage.

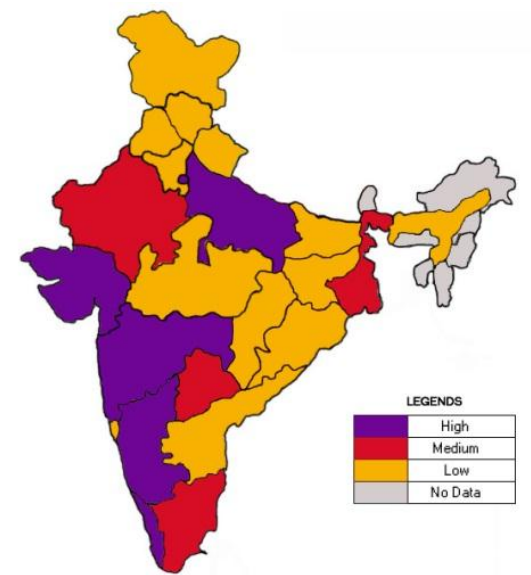

Figure 6. Result of Geo-Location Analysis

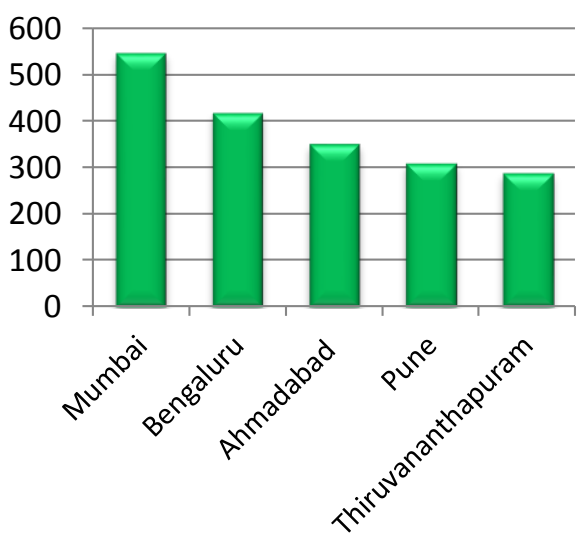

Figure 7. Top Cities with Highest DPM Usage

Inference: The results evidently point out that DPM usage is not uniform in India and more users are concentrated mainly in the south western states. The strong reasons for this asymmetry is due to these states being economically developed and having higher literacy rate. Maharashtra being the commercial capital of India tops the table with the highest number of users, closely followed by New Delhi. A closer analysis of top states shows that most people in these areas have access to mobile phone with internet and their higher literacy rates are significant factors in DPMs adoption. 


\section{Discussion}

Through this study, we tried to analyze the DPMs among Indian people employing Twitter as a tool. We applied different social media analytic techniques for identifying the various reasons that promote or oppose that usage of DPMs in India. Different social media techniques provided different insights but were really influential in depicting the possible factors that promote or oppose the usage of DPMs. Our results clearly showed that tweets related to mobile payments and mobile wallets constituted $43 \%(74,678)$ of the total tweets, indicating "mobility" and "ease of use" being the promoting factors that people get using these hand held devices. Another factor detected by us is the "cost of use" associated with the use of DPMs. This factor acts as a promoter in case of mobile payments where people not just make free transactions but also get benefits like cashbacks and offers [51] while it acts as an opposing factor in case of internet banking and credit/debit cards where people need to pay an addition service fees [52]. Similarly, "security" was another factor which was ambiguous playing the dual role of promoting as well as opposing factor. Some people felt secured with the use of DPMs for making financial transactions while there were people who demanded more secure and reliable transaction policies for DPMs. Even GOI is stressing on security factor, making it mandatory for mobile wallets to send SMS alerts and email for every transaction, so that more and more people can adopt these mechanisms [53]. The geo-location analysis shows that the DPM usage is not uniform in India. The two possible reasons for this are Information and Communications Technology (ICT) infrastructure and literacy rate. In India, a major chunk of population lives in rural areas where the education and infrastructure level are not at all at par with urban areas. This is a major hindrance in adoption of DPMs in these rural areas. So overall, mobility, ease of use, cost of use (Offers and Promotions), security, education and ICT infrastructure were the main promoting factors, while security, reliability, cost (Extra Service Charges) and lack of ICT infrastructure were the main opposing factors that created a negative opinion among people of India.

\section{Conclusions}

Technology is changing at a fast pace and it is making the life of mankind more comfortable and relaxing. DPM is one such area where technology has contributed extensively to completely transform it. The way of performing financial transactions has totally changed with introduction of E-Banking and M-Banking. Now, one can make transaction with just a click of button. Given this huge potential, still DPMs fail to reach its optimum potential. The aim of this research article was to analyze the adoption of DPMs in India using Twitter as a Tool. The analysis shows that though there has been a highly positive attitude among people but the number of users with negative opinion increases during later part of our sampling period due to the difficulties faced by the users. The main factors that promoted DPMs were mobility, ease of use, security, offers by the various wallets and better service. In contrast, the main factors which went against the adoption of DPMs were lack of security, 
inadequate infrastructure backup and unreliability. Another important finding of this research article is that DPMs are not uniformly used throughout India with the south western states dominating its use. The main reasons for this asymmetry are possibly higher literacy rate, financial strength and availability of mobile devices with internet connections.

Though we were able to get some valuable insights from this research about adoption of DPMs in India, it still leaves some open questions for researchers to carry forward their research in this area. These issues mainly include the reasons for polarization among supporters of DPMs. Similarly, why people are more intended towards mobile based DPMs as compared to other DPMs? All these questions need to be addressed in future work, which will help to understand the perception of bigger user base about DPMs' adoption in India.

\section{References}

1. Grover, P., Kar, A. K., \& Ilavarasan, P. V. (2017). Understanding Nature of Social Media Usage by Mobile Wallets Service Providers-An Exploration through SPIN Framework. Procedia computer science, 122, 292-299.

2. Patil, P. P., Dwivedi, Y. K., \& Rana, N. P. (2017, November). Digital payments adoption: an analysis of literature. In Conference on e-Business, e-Services and e-Society (pp. 61-70). Springer, Cham.

3. Patil, P. P., Rana, N. P., \& Dwivedi, Y. K. (2018, June). Digital Payments Adoption Research: A Meta-Analysis for Generalising the Effects of Attitude, Cost, Innovativeness, Mobility and Price Value on Behavioural Intention. In International Working Conference on Transfer and Diffusion of IT (pp. 194-206). Springer, Cham.

4. Kapoor, K. K., Dwivedi, Y. K., \& Williams, M. D. (2015). Examining the role of three sets of innovation attributes for determining adoption of the interbank mobile payment service. Information Systems Frontiers, 17(5), 1039-1056.

5. Jack, W., \& Suri, T. (2011). Mobile money: The economics of M-PESA (No. w16721). National Bureau of Economic Research.

6. Patil, P. P., Rana, N. P., \& Dwivedi, Y. K. (2018, October). Digital Payments Adoption Research: A Review of Factors Influencing Consumer's Attitude, Intention and Usage. In Conference on e-Business, e-Services and e-Society (pp. 45-52). Springer, Cham.

7. Grover, P., \& Kar, A. K. (2018). User engagement for mobile payment service providersintroducing the social media engagement model. Journal of Retailing and Consumer Services. DOI: https://doi.org/10.1016/j.jretconser.2018.12.002

8. Kapoor, K. K., Dwivedi, Y. K., \& Williams, M. D. (2015). Examining the role of three sets of innovation attributes for determining adoption of the interbank mobile payment service. Information Systems Frontiers, 17(5), 1039-1056.

9. Statista [Online], https://www.statista.com/outlook/296/100/digital-payments/worldwide

10. Augsburg, C., \& Hedman, J. (2014, August). Value added services and adoption of mobile payments. In Proceedings of the Sixteenth International Conference on Electronic Commerce (p. 27). ACM.

11. Kapoor, K. K., Tamilmani, K., Rana, N. P., Patil, P., Dwivedi, Y. K., \& Nerur, S. (2018). Advances in social media research: past, present and future. Information Systems Frontiers, 20(3), pp. 531-558

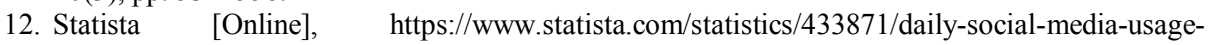
worldwide/

13. Singh, P., Dwivedi, Y. K., Kahlon, K. S., Sawhney, R. S., Alalwan, A. A., \& Rana, N. P. (2019). Smart Monitoring and Controlling of Government Policies Using Social Media and Cloud 
Computing. Information Systems Frontiers, 1-23. DOI: https://doi.org/10.1007/s10796-01909916-y

14. Alalwan, A. A., Rana, N. P., Dwivedi, Y. K., \& Algharabat, R. (2017). Social media in marketing: A review and analysis of the existing literature. Telematics and Informatics, 34(7), 1177-1190.

15. Dwivedi, Y. K., Kapoor, K. K., \& Chen, H. (2015). Social media marketing and advertising. The Marketing Review, 15(3), 289-309.

16. Singh, N. K., Sahu, G. P., Rana, N. P., Patil, P. P., \& Gupta, B. (2018, June). Critical Success Factors of the Digital Payment Infrastructure for Developing Economies. In International Working Conference on Transfer and Diffusion of IT (pp. 113-125). Springer, Cham.

17. Siu, N. Y. M., \& Mou, J. C. W. (2005). Measuring service quality in internet banking: the case of Hong Kong. Journal of International Consumer Marketing, 17(4), 99-116.

18. Sahu, G. P., \& Singh, N. K. (2017, November). Paradigm Shift of Indian Cash-Based Economy to Cash-Less Economy: A Study on Allahabad City. In Conference on e-Business, e-Services and e-Society (pp. 453-461). Springer, Cham.

19. Baabdullah, A. M., Alalwan, A. A., Rana, N. P., Patil, P., \& Dwivedi, Y. K. (2019). An integrated model for m-banking adoption in Saudi Arabia. International Journal of Bank Marketing, 37(2), pp. 452-478.

20. Alalwan, A. A., Dwivedi, Y. K., \& Rana, N. P. (2017). Factors influencing adoption of mobile banking by Jordanian bank customers: Extending UTAUT2 with trust. International Journal of Information Management, 37(3), 99-110.

21. Sharma, S. K., \& Sharma, M. (2019). Examining the role of trust and quality dimensions in the actual usage of mobile banking services: An empirical investigation. International Journal of Information Management, 44, 65-75.

22. Singh, P., Sawhney, R. S., \& Kahlon, K. S. (2018). Sentiment analysis of demonetization of 500 \& 1000 rupee banknotes by Indian government. ICT Express, 4(3), 124-129.

23. Digital India [Online], https://digitalindia.gov.in/content/about-programme

24. Oliveira, T., Thomas, M., Baptista, G., \& Campos, F. (2016). Mobile payment: Understanding the determinants of customer adoption and intention to recommend the technology. Computers in Human Behavior, 61, 404-414.

25. Slade, E., Williams, M., Dwivedi, Y., \& Piercy, N. (2015). Exploring consumer adoption of proximity mobile payments. Journal of Strategic Marketing, 23(3), 209-223.

26. Slade, E. L., Dwivedi, Y. K., Piercy, N. C., \& Williams, M. D. (2015). Modeling consumers' adoption intentions of remote mobile payments in the United Kingdom: extending UTAUT with innovativeness, risk, and trust. Psychology \& Marketing, 32(8), 860-873.

27. Schierz, P. G., Schilke, O., \& Wirtz, B. W. (2010). Understanding consumer acceptance of mobile payment services: An empirical analysis. Electronic commerce research and applications, 9(3), 209-216.

28. Smartphones in India [Online], https://yourstory.com/2017/10/india-530m-smartphone-users2018

29. Mobile Internet Users in India [Online], https://www.bloombergquint.com/business/mobileinternet-users-in-india-seen-at-478-million-by-june-says-report\#gs.31o483

30. Digital Payment Industry in India [Online], https://www.orbisresearch.com/reports/index/digitalpayment-systems-market-in-india-drivers-opportunities-trends-and-forecasts-to-2022

31. Singh, P., Kahlon, K. S., Sawhney, R. S., Vohra, R., \& Kaur, S. (2018). Social media buzz created by\# nanotechnology: insights from Twitter analytics. Nanotechnology Reviews, 7(6), 521-528.

32. Whiting, A., \& Williams, D. (2013). Why people use social media: a uses and gratifications approach. Qualitative Market Research: An International Journal, 16(4), 362-369.

33. Singh, J. P., Irani, S., Rana, N. P., Dwivedi, Y. K., Saumya, S., \& Roy, P. K. (2017). Predicting the "helpfulness" of online consumer reviews. Journal of Business Research, 70, 346-355.

34. Sharma, N., \& Patterson, P. G. (1999). The impact of communication effectiveness and service quality on relationship commitment in consumer, professional services. Journal of Services Marketing, 13(2), 151-170.

35. Twitter API [Online], https://www.nuget.org/packages/TweetinviAPI/ 
36. Liu, Y., Chen, Y., Wu, S., Peng, G., \& Lv, B. (2015). Composite leading search index: a preprocessing method of internet search data for stock trends prediction. Annals of Operations Research, 234(1), 77-94.

37. García, S., Luengo, J., \& Herrera, F. (2016). Data preprocessing in data mining. Springer. DOI: 10.1007/978-3-319-10247-4

38. R-Language [Online], https://www.r-project.org/about.html

39. Stieglitz, S., \& Dang-Xuan, L. (2013). Emotions and information diffusion in social mediasentiment of microblogs and sharing behavior. Journal of Management Information Systems, 29(4), 217-248

40. Grover, P., Kar, A. K., Dwivedi, Y. K., \& Janssen, M. (2018). Polarization and acculturation in US Election 2016 outcomes-Can twitter analytics predict changes in voting preferences. Technological Forecasting and Social Change.

41. Chae, B. K. (2015). Insights from hashtag\# supplychain and Twitter Analytics: Considering Twitter and Twitter data for supply chain practice and research. International Journal of Production Economics, 165, 247-259.

42. Aswani, R., Kar, A. K., Ilavarasan, P. V., \& Dwivedi, Y. K. (2018). Search engine marketing is not all gold: Insights from Twitter and SEOClerks. International Journal of Information Management, 38(1), 107-116.

43. Miao, M., Jiang, T., \& You, I. (2015). Payment-based incentive mechanism for secure cloud deduplication. International Journal of Information Management, 35(3), 379-386.

44. Singh, P., Sawhney, R. S., \& Kahlon, K. S. (2017, November). Forecasting the 2016 US presidential elections using sentiment analysis. In Conference on e-Business, e-Services and eSociety (pp. 412-423). Springer, Cham.

45. Ou, G., Chen, W., Wang, T., Wei, Z., Li, B., Yang, D., \& Wong, K. F. (2014). Exploiting Community Emotion for Microblog Event Detection. In EMNLP (pp. 1159-1168).

46. Mohammad, S. M., \& Turney, P. D. (2010, June). Emotions evoked by common words and phrases: Using mechanical turk to create an emotion lexicon. In Proceedings of the NAACL HLT 2010 workshop on computational approaches to analysis and generation of emotion in text (pp. 26-34). Association for Computational Linguistics.

47. HerdaĞdelen, A., Zuo, W., Gard-Murray, A., \& Bar-Yam, Y. (2013). An exploration of social identity: The geography and politics of news-sharing communities in twitter. Complexity, 19(2), $10-20$.

48. Amirkhanyan, A., \& Meinel, C. (2017, November). Density and intensity-based spatiotemporal clustering with fixed distance and time radius. In Conference on e-Business, e-Services and eSociety (pp. 313-324). Springer, Cham.

49. Singh, P., Sawhney, R. S., \& Kahlon, K. S. (2019). Twitter Based Sentiment Analysis of GST Implementation by Indian Government. In Digital Business (pp. 409-427). Springer, Cham.

50. Singh, J. P., Dwivedi, Y. K., Rana, N. P., Kumar, A., \& Kapoor, K. K. (2017). Event classification and location prediction from tweets during disasters. Annals of Operations Research, 1-21.

51. Business Today [Online], https://www.businesstoday.in/sectors/banks/paytm-payments-bankaccount-interest-rate-offer-free-imps-neft-rupay-debit-card-transaction/story/264971.html

52. Times of India [Online], https:/timesofindia.indiatimes.com/business/india-business/sbi-atmonline-cash-transaction-fees-change-from-june-1-all-you-need-toknow/articleshow/58942912.cms

53. Times of India [Online], https://timesofindia.indiatimes.com/gadgets-news/rbi-sets-new-rules-toprotect-consumers-from-fraud-transactions-on-paytm-phonepe-or-other-mobilewallets/articleshow/67453118.cms 